\title{
Gender Identity Disorder
}

National Cancer Institute

\section{Source}

National Cancer Institute. Gender Identity Disorder. NCI Thesaurus. Code C94362.

A disorder characterized by a strong and persistent cross-gender identification (such as stating a desire to be the other sex or frequently passing as the other sex) coupled with persistent discomfort with his or her sex (manifested in adults, for example, as a preoccupation with altering primary and secondary sex characteristics through hormonal manipulation or surgery). 